\title{
La littérature hongroise en komi
}

The Hungarian Literature in the Komi Language

Magyar irodalom komi nyelven

\section{Nikolaj Rakin}

Traducteur : Eva Toulouze

\section{(2) OpenEdition}

1 Journals

Édition électronique

URL : https://journals.openedition.org/efo/9546

DOI : 10.4000/efo.9546

ISSN : 2275-1947

Éditeur

INALCO

Référence électronique

Nikolaj Rakin, «La littérature hongroise en komi », Études finno-ougriennes [En ligne], 49-50 | 2018, mis en ligne le 28 janvier 2019, consulté le 08 juillet 2021. URL : http://journals.openedition.org/efo/9546 ; DOI : https://doi.org/10.4000/efo.9546

Ce document a été généré automatiquement le 8 juillet 2021

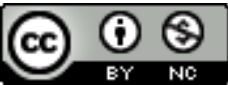

Études finno-ougriennes est mis à disposition selon les termes de la Licence Creative Commons Attribution - Pas d'Utilisation Commerciale 4.0 International. 


\title{
La littérature hongroise en komi
}

\author{
The Hungarian Literature in the Komi Language \\ Magyar irodalom komi nyelven
}

\author{
Nikolaj Rakin \\ Traduction : Eva Toulouze
}

1 La première publication de traductions en komi d'auteurs hongrois remonte à 1928. Cette année-là, voit le jour dans la revue ордым (« sentier ») le poème de Sándor Petőfi « Nuit » (Komi : вой, hong. Éj van...), traduit par V. I. Lytkin. On peut considérer cette date comme le point de départ d'un processus qui se poursuit jusqu'à nos jours, la découverte par les lecteurs komis de la littérature hongroise. En 2014, dans une thèse intitulée Le Kalevala en komi dans le contexte de certains aspects de la théorie et de la pratique de la traduction littéraire, où je présentais l'histoire des traductions depuis les langues finno-ougriennes (dont le hongrois), je notais qu'on pouvait lire en komi, d'après mes estimations, cinquante-huit œuvres de vingt-neuf auteurs hongrois (sans tenir compte des traductions d'œuvres d'oralité (Rakin, 2014A, p. 19-20 ; Rakin, 2015), mais dès 2016, le nombre des auteurs dépassait les soixante et celui des œuvres, les cent vingt. Ceci tient avant tout au fait qu'en 2015 plus de cinquante nouvelles traductions sont parues dans des anthologies de prose et de poésie hongroise, ainsi qu'à la découverte sur la base de recherches acharnées, d'œuvres antérieures inconnues auparavant.

2 L'histoire de la parution des traductions komies peut se subdiviser en trois périodes : la fin des années 1920-1920, les années 1950-1980 et la période après 1990. La première période est marquée par le nom de V.I. Lytkin (Ill'ja Vas', 1895-1981). Il a été le premier à se tourner vers la traduction en komi d'œuvres hongroises. Nous lui devons aussi les premières traductions d'autres langues finno-ougriennes: du finnois (le Kalevala, J. Erkko) et l'oudmourte (Kuzebaj Gerd et Ašalči Oki) (Rakin, 2014A, p. 6465 ; Rakin, 2014b, p. 21, 25 ; Rakin, 2009 ; Rakin, 2016, p. 50-51 ; Rakin, 2014). En 1927, le poète et savant komi se trouvait à l'université à Budapest, et il a eu l'occasion d'y assimiler le hongrois et d'y découvrir la culture et la littérature hongroises. C'est bien à ce moment-là qu'il a traduit directement de l'original des poèmes de Sándor Petőfi « Nuit » (Komi : вой ; Hongrois : Éj van...) - et d'Endre Ady - « Les chevaux de la mort » 
(Кот. кулӧмлӧн вӧвъяС ; Hong. A halál lovai) ; à ceux-là s'ajoutent un poème d'un auteur moins connu, Gyula Szentessy (1870-1905), «Les années passent» (Kom. мунӧны войяс ; Hong. Mennek az évek) et un chant populaire «Le hanneton de mai» (Kom. КАльӧзУР; Hong. Cserebogár, sárga cserebogár). Ces traductions ont été publiées dans la revue Ordym $\left(1928, \mathrm{~N}^{\circ}\right.$ 9) et dans le recueil de poèmes «Poèmes" (Кom. Кывьурјас, 1929).

3 L'œuvre de Petőfi a continué à intéresser V.I. Lytkin, qui en a encore traduit des poèmes dans les années 1950-1970. C'est ainsi que dans le recueil «Au lever du soleil » (Кот. шонді ПЕтігӧн, 1959), il inclut les traductions suivantes, réalisées en 1956 : « Тu aimes le printemps... » (Кот. ГАЖА тУЛЫС доНА тэД...; Hong. Te a tavaszt szereted...), «Pain noir » (Kom. Сьӧд нянь ; Hong. Fekete kenyér), «La rivière a débordé... » (Kom. ТУӧМА ТАЙ ВАЫС ; Hong. Kicsapott a folyó...), « Un matin désagréable... » (Kom. АБУ ГАЖА AРСя АсыB ; Hong. Kellemetlen öszi reggel...), « Rêve» (Kom. BöT... ; Hong. Az álom). C'est en 1958 qu'il a traduit «Héros en haillons » (Кom. СЫРИ-ЛЕТКИ ПАСЬКӧМА ГЕРОЙЯС ; Hong. Rongyos vitézek), et, en 1973, «Pièce nationale» (Кom. НАЦИонАльНӧй сьылАнкыв; Hong. Nemzeti dal) et «Adieux » (Кom. янсӧдчӧм ; Hong. Bucsú), publiés dans la revue L'étoile du Nord (Кот. войвыв кодзув) respectivement en 1958 et 1973.

La maîtrise du hongrois, la parenté des deux langues concernées par le processus de traduction, sa préparation philologique et son talent de poète et de traducteur lui ont permis de proposer des traductions précises, correspondant à l'original, qui en transmettent non seulement le contenu mais aussi la forme.

5 V. I. Lytkin a principalement choisi de traduire des poèmes précoces de S. Petőfi, qui ne sont pas les plus significatifs ni les plus connus (à l'exception de "Pièce nationale »). Ceci s'explique sans doute par ce que ces textes, écrits dans le style populaire, étaient plus faciles que les autres à comprendre et à rendre en komi en raison de leur simplicité linguistique. De même leur thématique se rapprochait des œuvres de Lytkin lui-même en tant que poète et de manière générale de la littérature komie de l'époque.

6 Relèvent de la même époque les traductions motivées principalement par des soucis propagandistes et politiques. Ceci explique la parution en komi d'extraits du roman «La Tisza brûle » (Kom. тисса ЫПъялӧ, Hong. Ég a Tisza), de Béla Illés, révolutionnaire hongrois réfugié en Union Soviétique, ainsi que certains récits du même auteur.

7 La deuxième étape de l'histoire des traductions komies de la littérature hongroise commence dans les années 1950, après la fin de la Deuxième Guerre mondiale, quand la Hongrie devient l'un des États du bloc socialiste. À cette époque-là, la littérature hongroise intéresse en tant que production d'un pays frère, dans le cadre d'un processus ciblé de découverte mutuelle des peuples de l'URSS et des pays socialistes. Ainsi assiste-t-on de temps en temps, entre 1950 et 1980, à la parution, dans les colonnes de L'Étoile du Nord de traductions de classiques hongrois du XIX début $\mathrm{xx}^{\mathrm{e}}$ siècle, ainsi que d'auteurs de l'époque, comme par exemple des écrivains d'outre-Carpathes écrivant en hongrois. Quelques exemples : en poésie, Sándor Petőfi, «J'ai rêvé de la guerre... » (Коті : ВОЙНА ЛЁК ВӧтӧН ПЕТКӧдчИЛіС МЕМ..., МЕМ ВОЙНА УСИС вӧтӧН...; Hong. Háborúval almodám...), «Je serai un arbre si...» (Кот. тЭ Кӧ ДзоРид; Hong. Fa leszek, ha...), «Le garçon cagneux » (Кот. чуКля коКА зоН; Hong. А csámpás legény) ; János Vajda, «La comète» (Kom. КOMETA ; Hong. Az üstökös); Árpád Tóth, « MArs » (Kom. MAPT; Hong. Március) ; Ferenc Buda, «Le conte en pierre » (Kom : ИзъЯ мойд; Hong. Kőból rakott mese); Gábor Garai, «Juin » (Кom. июнь; Hong. Június), etc. 
En prose mentionnons Zsigmond Móricz, «Manger une fois à sa faim » (Kom. Кöть ӧтчыд пӧттӧдз сёйны; Hong. Egyszer jóllakni).

8 La littérature hongroise sub-carpathique est représentée par les récits de László Balla et de Vilmos Kovács, et les poèmes pour enfants de Borbála Szalai. Les traductions de cette époque s'appuyaient sur des traductions russes déjà existantes.

C'est à cette époque qu'on commence à publier, dans L'Étoile du Nord, ainsi que dans les journaux de niveau républicain comme Chemin lumineuх (югыд туй) et Le drapeau rouge, des articles dédiés à des écrivains et chercheurs hongrois, aux relations hungaro-komies, aux voyages d'intellectuels komis en Hongrie, etc. Par exemple: «ВЕНГРИЯСА ГИЖЫСЬ ЖИГМОНД МОРИЦ чУЖАН ЛУНСЯНь 100 Во» («Les cent ans de la naissance de l'écrivain hongrois Zsigmond Móricz ", L'Étoile du Nord, 1979, $\mathrm{N}^{\circ} 7$ ); A. I. Turkin «ВЕНГРИЯЛӧН ПЕРВОЙ ПОэТ (ШАНДОР ПЕТЁФИ ЧУЖАН ЛУНСЯНЬ 150 вО ТЫРИГКЕЖЛ̈̈) » (Le premier poète hongrois. (Pour les 150 ans de la naissance de Sándor Petőfi ; L'Étoile du Nord, 1973, № 1); А. I. Turkin « ИЛЛЯ ВАСЬ - ШАНДОР ПЕТЁФИӧС комиӧдысь » (Ill'ja Vas', traducteur de Sándor Petőfi) ; L'Étoile du Nord, 1979, № 12) ; «ВЕНГРЪЯСЛӧН ДА КОмИЯСЛӧН ЙИТӧДъЯС ( Relations des Komis avec les Hongrois; L'Étoile du Nord, 1977, № 9) ; Péter Domokos, «КомИ ДА ВЕНГРИЯ» (Komi et la Hongrie), L'Étoile du Nord, 1970, № 7), A. I. Turkin « Dans les langues de Petőfi et de Kuratov », Le drapeau rouge, 20.07.1967).

10 La troisième étape dans l'histoire des traductions d'œuvres hongroises est liée eu développement du mouvement finno-ougrien en 1990-2000. C'est alors que se forme l'Association pour les littératures finno-ougriennes et les écrivains qui écrivent dans une langue finno-ougrienne se rassemblent régulièrement en Congrès. Cette coopération littéraire débouche sur la publication de diverses anthologies d'auteurs finno-ougriens. C'est ainsi qu'à Syktyvkar ont été édités les recueils УНА РӧМА сикӧтш. ( «a couleur du collier», 2002) et льӧм ю («Rivière de merises", 2008), où ont été intégrées les traductions susnommées de Petőfi, Vajda, Garai, Buda ainsi que la traduction de l'hymne hongrois et des poèmes de József Szervác, József Tornai, József Utassy, Anna Kiss et István Bella.

11 Dans les années 2000, les traductions d'œuvres hongroises paraissent en komi (ainsi que dans les autres langues finno-ougriennes) sur initiative des Hongrois eux-mêmes et avec leur soutien. C'est à l'occasion du XIII ${ }^{\mathrm{e}}$ congrès des écrivains finno-ougriens, tenu en septembre 2015 à Badacsonytomaj en Hongrie, qu'à l'initiative de János Pusztay toute une série d'anthropologies ont été éditées dans les langues finno-ougriennes : Les douze meilleures nouvelles hongroises, Les cinquantemeilleurs poèmes hongrois, Les douze meilleurs poèmes des littératures finno-ougriennes; quelques années auparavant, en 2012, avait vu le jour le recueil Les douze meilleurs poèmes hongrois. Grâce à ces anthologies, sont désormais représentés en komi tous les principaux auteurs hongrois, aussi bien poètes que prosateurs, et leurs œuvres les plus significatives, depuis les périodes les plus anciennes jusqu'à nos jours. Par exemple, le recueil Les douze meilleures nouvelles hongroises ( ВЕНГЕР ЛИТЕРАТУРАЫСЬ 12 мЕДСЯ МИЧА ВИСЬТ) contient les traductions suivantes :

• Mór Jókai, « Lequel des neuf ? » (Кот. кодӧс ӧкмыс пӧвстысь ; Hong. Melyiket a kilenc közül?) ;

- Frigyes Karinthy, « Barabbas » (Kom. BAPABBA ; Hong. Barabbás) ;

• Dezső Kosztolányi, « La clé » (Кот. Ключ ; Hong. A kulcs) ;

• Iván Mándy, « Le mannequin » (Кот. БАТЯ-ПИА ; Hong. A modell) ; 
- Kálmán Mikszáth, «Le paysan qui a acheté une faux » (Kom. КосА НьӧБысь КРЕСтьянин; Hong. A kaszát vásárló paraszt) ;

-Zsigmond Móricz, « Les barbares » (Kom. НЕМОРТъЯС ; Hong. Barbárok) ;

- Géza Ottlik, «Le sculpteur et la mort » (Kom. скУльптоР дА сурым; Hong. A müvész és a halál) ;

•István Tömörkény, «Combat avec le soldat» (Kom. солдАткӧд тыш; Hong. Csata a katonával) ;

- Péter Hajnóczy, «La fourmi et la cigale » (Kom. кодзУвкот дА тИРГАН; Hong. A hangya és a tücsök) ;

- Ferenc Sánta, « Nous étions nombreux » (Kom. Ӧти Рытӧ ; Hong. Sokan voltunk);

-Imre Sarkadi , Kelemen, le tailleur de pierres » (Kom. Из тЕчЫСь КЕЛЕМЕН; Hong. Kömüves Kelemen) ;

- István Örkény, « Ballade sur la puissance de la poésie » (Kom. поэзия Вын Йылысь БАлЛАДАn; Hong. Ballada a költészet hatalmáról).

12 À l'étape actuelle, comme avant, la plupart des traductions se font, non point depuis l'original hongrois, mais par l'intermédiaire du russe. La différence est que pour leurs traductions, les traducteurs ne partent pas des traductions littéraires russes existantes, mais des traductions littérales réalisées par des spécialistes du hongrois, de la littérature et de la culture hongroises. C'est pourquoi les traductions de la dernière période sont beaucoup plus proches de l'original hongrois que celles des années 1950-1980, et rendent compte de manière beaucoup plus fidèle du contenu, de l'idée centrale et de la forme des textes originaux.

Certains textes, cependant, sont traduits directement en komi depuis le hongrois, sans langue intermédiaire: ce sont les contes hongrois, traduits par E. A. Igušev, N. D. Manova et N. A. Rakin, des traducteurs qui maîtrisent le hongrois. N. D. Manova a publié à différentes époques quatre recueils de traductions de prose narrative: МАДЬЯРЪЯСЛӧН МАТЯШ кОРОЛЬ ЙЫЛЫСЬ МОЙДъЯС («Contes et légendes du roi hongrois Mattiás », 2000, 2016), ПЕМӧсъЯС ЙЫЛЫСЬ МАДЬЯР МОЙДЪЯС («Contes hongrois d'animaux », 2006), вӧВЛӧМТОР? АЛИ ВӧВЛЫТӧМТОР? МАДЬЯР ПРИТЧАЯС (« Cela a eu lieu ? ou non? Paraboles hongroises », 2010). Les contes traduits par E. A. Igušev et N. A. Rakin sont publiés dans la revue pour enfants Би кинь (« Étincelle »). De plus on trouve en komi quelques chants populaires.

Sur toutes les œuvres traduites, c'est la poésie qui domine largement tous les autres genres. L'auteur le plus traduit est Sándor Petőfi. Pendant tout le $\mathrm{xx}^{\mathrm{e}}$ siècle, les traducteurs komis se sont tournés vers cet auteur, certains poèmes ont même été traduits deux fois. La grande masse des traductions est publiée dans les périodiques (comme la revue L'étoile du Nord) ou dans des anthologies. Ces dernières années celles-ci ne sont pas éditées directement en République Komie, mais à l'étranger, en Hongrie. Le petit tirage des périodiques et des anthologies et la publication de ces dernières à l'étranger expliquent que malgré la bonne représentation de la littérature hongroise en komi, cette dernière demeure regrettablement mal connue des lecteurs komis. 


\section{BIBLIOGRAPHIE}

RAKIN Nikolaj Anatolevich, 2014, "Mutual Komi - Finnish Translations" in Mitteilungen der societas uralo altaica, 30. Internationale Finnougristik Studierendenkonferenz. Georg August Universität Göttingen, 9.-12. April 2014. Zusammenfassungen, vol. Heft 28, pp. 104-105.

RAKIN Nikolaj Anatolevich, 2015, “Hungarian - Komi and Komi - Hungarian Translations”, in XXXI. International Finno Ugric Students' conference. Pécsi Tudományegyetem. 15.-18.04.2015. Abstracts, Pécs University Press, Pécs, pp. 82-83.

RAKIN Nikolaj Anatolevich РАКИН НИКОЛАЙ АНАТОЛЬЕВИЧ, 2009, «О НЕКОТОРЫХ ФИННО УГОРСКИХ ПЕРЕВОДАХ „КАЛЕВАЛЫ” [Sur certaines traductions finno-ougriennes du Kalevala] in ФИнНО УГРОВЕДЕНИЕ [Finno-ougristique], vol. 2, pp. 69-76.

RAKIN Nikolaj Anatolevich РАКИН НИКОЛАЙ АНАТОЛЬЕВИЧ, 2014, «КАЛЕВАЛА» НА КОМИ ЯЗЫКЕ В КОНТЕКСТЕ НЕКОТОРЫХ АСПЕКТОВ ТЕОРИИ И ПРАКТИКИ ХУДОЖЕСТВЕННОГО ПЕРЕВОДА [Le Kalevala en komi dans le contexte de certaines dimensions de la théorie et de la pratique de la traduction littéraire], University of Tartu Press, Tartu, 229 p.

RAKIN Nikolaj Anatolevich РАКИН НИКОЛАЙ АНАТОЛЬЕВИЧ, 2014, «ПРИЛОЖЕНИЯ К РАБОТЕ “„КАЛЕВАЛА” НА КОМИ ЯЗЫКЕ В КОНТЕКСТЕ НЕКОТОРЫХ АСПЕКТОВ ТЕОРИИ И ПРАКТИКИ ХУДОЖЕСТВЕННОГО ПЕРЕВОДА" [Annexe au Kalevala en komi dans le contexte de certaines dimensions de la théorie et de la pratique de la traduction littéraire]», in «КАЛЕВАЛА» НА КОМИ ЯЗЫКЕ В КОНТЕКСТЕ НЕКОТОРЫХ АСПЕКТОВ ТЕОРИИ И ПРАКТИКИ ХУДОЖЕСТВЕННОГО ПЕРЕВОДА [Lе Kalevala en komi dans le contexte de certaines dimensions de la théorie et de la pratique de la traduction littéraire], University of Tartu Press, Tartu.

RAKIN Nikolaj Anatolevich РАКИН НИКОЛАЙ АНАТОЛЬЕВИЧ, 2016, “„КАЛЕВАЛА” НА КОМИ ЯЗЫКЕ: ПЕРЕВОДЫ В. И. ЛЫТКИНА, А. И. ТУРКИНА, А. ИСТОМИНОЙ, М. ЕЛЬКИНА, В. Т. ЧИСТАЛЕВА» [Le Kalevala en komi : les traductions de V. I. Lytkin, A. I. Turkin, A. Istomina, M. El'kin, V. T. Čistalev] in ЕЖЕГОДНИК ФИнНО УГОРСКИХ ИСслЕДОВАНИЙ [Annuaire des recherches finnoougriennes], $\mathrm{n}^{\circ} 2$, vol. 10, pp. 49-57.

\section{RÉSUMÉS}

Les premières traductions komies d'œuvres hongroises ont eu lieu dans les années 1920. Aujourd'hui, tous les principaux auteurs hongrois (poètes ou prosateurs) sont représentés en komi ainsi que leurs œuvres les plus significatives, depuis les périodes les plus anciennes jusqu'à nos jours. L'histoire de la parution des traductions komies peut se subdiviser en trois périodes: la fin des années 1920-1930, les années 1950-1980 et la période après 1990. La première période est liée au travail de V.I. Lytkin, savant et poète komi, qui traduisait directement du hongrois. Dans les années 1950-1980, les traductions ont eu lieu dans le cadre d'une découverte systématique mutuelle des cultures et littératures des peuples de l'URSS et des pays socialistes, et s'appuyaient sur des traductions russes déjà existantes. La période postérieure à 1990 va de pair avec l'émergence du mouvement finno-ougrien. Ces dernières années les traductions se font à l'initiative et avec le soutien des Hongrois eux-mêmes. D'après mes estimations, les œuvres traduites sont de l'ordre de cent vingt, de presque soixante auteurs. Les Komis traduisent surtout de la poésie, et l'auteur le plus traduit est S. Petőfi. La plupart des traductions paraissent dans les périodiques ou dans des anthologies. 
The first translations of Hungarian literature on the Komi language appeared in the 1920s. Nowadays on the Komi language you can read all the major Hungarian authors (both poets and prose writers) and their most significant works from the early periods of Hungarian literature to the present. The history of the Komi translation can be divided into 3 periods: the late 1920s-1930s, 1950s-1980s and the period after 1990. The first period is associated with the Komi scientist and poet V. I. Lytkin who have translated directly from Hungarian. In the 1950s1980s the translations were carried out in the framework of the process of mutual acquaintance with cultures and literatures of the peoples of the USSR and socialist countries and was done mostly from existing Russian literary translations. The period after 1990 is associated with the birth and development of the Finno-Ugric movement. In recent years, the translations of Hungarian works appear on the initiative and with the support of the Hungarians themselves. In total, according to our calculations, about 120 works of almost 60 Hungarian authors are translated into Komi.Translations of poetry prevail over prose. The poetry of Petőfi Sándor is the most translated into Komi. The bulk of the translations are published in periodicals or in anthologies.

A magyar irodalmi alkotások első komi nyelvű fordításai az 1920-as években jelentek meg. Napjainkban már a legjelentősebb magyar írók (egyaránt költők és prózaírók) művei olvashatók komiul, a magyar irodalom minden korszakából. A magyar irodalom komi fordításának története három időszakra osztható fel: az első az 1920-as évek végét és az 1930-as éveket öleli fel, a második az 1950-es évektől az 1980-as évek végéig terjed, a harmadik pedig az 1990 utáni időszak. Az első periódus a magyar költészetet közvetlenül magyarból fordító komi költő és tudós, V. I. Litkin nevéhez köthető. 1950 és 1990 között a fordítások a Szovjetunió és a szocialista országok népeinek kultúráival és irodalmaival való kölcsönös megismerkedés folyamata keretében jelentek meg. Az 1990 utáni időszak a finnugor mozgalom születésével és kibontakozásával hozható összefüggésbe. Az utóbbi években a komi fordítások a magyarok saját kezdeményezésére és támogatásával jelennek meg. Számításunk szerint komi nyelven közel 60 magyar író mintegy 120 alkotása férhető hozzá. A legtöbb fordítás versfordítás, a leggyakrabban fordított szerző pedig Petőfi Sándor. A fordítások zöme időszaki kiadványokban és antológiákban jelenik meg.

\section{INDEX}

motscleset luule, tõlked, tõlkijad, ungari kirjandus, kirjandus, tõlge, 20. sajand, 21. sajand, algus, komi, vene, Badacsonytomaj, Budapest, Sõktõvkar, Ungari

Keywords : Hungarian literature, poetry, littérature, translations, translators, 20th century, 21th century beginning, Komi, Russian, Badacsonytomaj, Budapest, Hungary, Syktyvkar

Mots-clés : littérature hongroise, poésie, traducteurs, littérature, traductions, XXe siècle, XXIe siècle début, komi, russe, Badacsonytomaj, Budapest, Hongrie, Syktyvkar 